\title{
Datação Sm-Nd em rocha total e granada do metamorfismo granulítico da região de Tartarugal Grande, Amapá Central
}

\author{
Elma Costa Oliveira ${ }^{1}$, Jean-Michel Lafon ${ }^{1}$, Simone Maria Costa Lima Gioia ${ }^{2}$ \& \\ Márcio Martins Pimentel ${ }^{2}$
}

\begin{abstract}
Resumo O procedimento experimental do método Sm-Nd utilizado no laboratório de Geologia Isotópica Pará-Iso (Universidade Federal do Pará) é apresentado detalhadamente para poder ser utilizado como referência pelos usuários do laboratório. A datação $\mathrm{Sm}-\mathrm{Nd}$ de granulitos félsicos da área de Tartarugal Grande, nordeste do Bloco Arqueano Amapá, (sudeste do Escudo das Guianas) forneceu idades isocrônicas rocha totalgranada de $2017 \pm 12 \mathrm{Ma}, 1981,6 \pm 2,8 \mathrm{Ma}$ e $2018 \pm 2,3 \mathrm{Ma}$. A análise das mesmas amostras no Laboratório de Geocronologia (Universidade de Brasília) indicou idades de $2037 \pm 8,4 \mathrm{Ma}, 1988 \pm 11 \mathrm{Ma}$ e $2013 \pm 15 \mathrm{Ma}$, respectivamente. Esses resultados indicam que temperaturas acima de $700^{\circ} \mathrm{C}$ foram alcançadas pelos granulitos de Tartarugal Grande entre 2,04-1,98 Ga, comprovando uma idade tardi-Transamazônica para o evento de alto grau metamórfico, na região nordeste do Bloco Arqueano Amapá. As idades-modelo $\mathrm{T}_{\mathrm{DM}}(\mathrm{Nd})$ entre 3,15 Ga e 2,79 Ga constituem mais um registro do evento principal de acresção crustal mesoarqueano, já identificado na porção sudeste do Escudo das Guianas.
\end{abstract}

Palavras-Chave: Sm-Nd, procedimento experimental, metamorfismo, granada, Orogênese Transamazônica.

\begin{abstract}
Sm-Nd whole rock-garnet dating of the granulite metamorphism from the Tartarugal Grande area, Central Amapá region. The experimental procedure for Sm-Nd method performed at the Pará-Iso Isotope Geology laboratory, (Federal University of Pará) is described in details as a reference for the customers of the Pará-Iso. Sm-Nd dating of felsic granulites from the Tartarugal Grande area, northeastern of the Archean Amapá Block, (Southeastern Guyana Shield) furnished whole rock - garnet isochron ages of 2017 $\pm 12 \mathrm{Ma}, 1981.6 \pm 2.8 \mathrm{Ma}$ e $2018 \pm 2.3 \mathrm{Ma}$. Dating of the same samples at the UnB geochronological laboratory yielded ages of $2037 \pm 8.4 \mathrm{Ma}, 1988 \pm 11 \mathrm{Ma}$ e $2013 \pm 15 \mathrm{Ma}$, respectively. Such results indicate that temperature of at least $700^{\circ} \mathrm{C}$ was reached by the Tartarugal Grande granulites between $2.04-1.98 \mathrm{Ga}$, as a proxy of a late Transamazonian high grade metamorphic event in the northeastern sector of the Archean Amapá Block. $\mathrm{T}_{\mathrm{DM}}(\mathrm{Nd})$ model ages between $3.15 \mathrm{Ga}$ and $2.79 \mathrm{Ga}$ are a further evidence of a major Mesoarchean crustal growth episode in the southeastern Guyana Shield.
\end{abstract}

Keywords: Sm-Nd, experimental procedure, metamorphism, garnet, Transamazonian Orogeny.

INTRODUÇÃO A aplicação do método Sm-Nd em estudos geológicos tem permitido um grande avanço na investigação dos processos de formação e retrabalhamento da crosta continental, uma vez que esta sistemática apresenta algumas características singulares, ligadas às propriedades geoquímicas dos elementos terras raras (ETR), que the imprimem determinadas vantagens sobre outros sistemas geocronológicos (DePaolo 1988, Faure $\&$ Mensing 2005). O método Sm-Nd tem sido também utilizado com sucesso para a datação de eventos metamórficos de alto grau, utilizando paragênese minerais formada durante o metamorfismo, como por exemplo, a granada (Cohen et al. 1988, Mezger et al. 1992).

Este trabalho tem dois objetivos, sendo o primeiro determinar, pelo método $\mathrm{Sm}-\mathrm{Nd}$ em rocha total e granada, a idade do evento metamórfico granulítico que afeta a região central do Amapá, localizada no extremo sudeste do Escudo das Guianas. O segundo objetivo é apresentar o procedimento experimental do método Sm-Nd utilizado no laboratório de Geologia Isotópica da UFPA (Pará-Iso), o qual foi desenvolvido por Kelley (1982) e Hayward (1983) e descrito em (Moura 1992). Esse procedimento difere daquele utilizado nos outros laboratórios de geocronologia no Brasil, como no Laboratório de Geocronologia (Universidade de Brasília) (Gioia \& Pimentel 2000), Laboratório de Geocronologia (Universidade de São Paulo) (Sato et al 1995) e Laboratório de Geologia Isotópica (Universidade Federal do Rio Grande do Sul) (Borba et al. 2006). Em uma primeira parte, será portanto apresentada uma descrição detalhada do procedimento experimental de análise $\mathrm{Sm}$ e Nd e, em seguida, serão apresentados resultados isotópicos Sm-Nd obtidos no laboratório Pará-Iso e no de Geocronologia da UnB, em rocha total (RT) e granada de granu-

1 - Laboratório de Geologia Isotópica, Instituto de Geociências, Universidade Federal do Pará, Belém (PA), Brasil.

E-mails: ecoliveira2002@yahoo.com.br, lafonjm@uafpa.br

2 - Laboratório de Geocronologia, Instituto de Geociências, Universidade Federal de Brasília, Brasília (DF), Brasil.

E-mails: sgioia@igc.usp.br,marcio@unb.br 
litos félsicos de Tartarugal Grande, na região central do Amapá, borda norte do Bloco Arqueano Amapá.

CONTEXTO GEOLÓGICO REGIONAL A região central do Amapá constitui a extremidade sudeste do Escudo das Guianas. Do ponto de vista geotectônico, a porção sudeste do Escudo das Guianas - SEG, englobada na Província Maroni-Itacaiúnas - PMI, insere-se em um modelo de evolução do Cráton Amazônico que envolve um extenso núcleo de crosta continental antiga preservada e estabilizada desde o Arqueano, circundado por faixas móveis de idades proterozóicas (Cordani et al. 1979, Cordani \& Neves 1982, Teixeira et al. 1989, Tassinari \& Macambira 1999, Santos et al. 2000, Tassinari et al. 2000, Tassinari \& Macambira 2004). A PMI teve sua evolução relacionada à Orogênese Transamazônica, no período entre 2,25 Ga e 1,95 Ga (Tassinari \& Macambira 1999, Tassinari et al. 2000, Delor et al. 2003a e b).

Um quadro lito-estrutural atualizado do SEG foi elaborado, enfatizando o crescimento multi-episódico dos terrenos riacianos com formação de crosta oceânica $(2,25-2,20 \mathrm{Ga})$, e seu retrabalhamento para produzir terrenos TTG-greenstone (2,18-2,13 Ga) e magmatismo granítico $(2,10-2,08 \mathrm{Ga})$ em contextos de colisão frontal e cisalhamento sinistral, respectivamente (Vanderhaege et al. 1998, Tassinari et al. 2000, Delor et al. 2003a). O arcabouço estrutural final resulta de extensão crustal e boudinage em escala continental, envolvendo upwelling mantélico e formação de faixas granulíticas $(2,08-2,02$ $\mathrm{Ga}$ ), inclusive de ultra alta temperatura - UAT no Suriname (De Roever et al. 2003, Delor et al. 2003b).

Nesse contexto, o Estado do Amapá pode ser dividido em um domínio norte, onde predominam granitóides e ortognaisses paleoproterozóicos (Fig. 1), e um domínio centro-sul onde predominam rochas arqueanas retrabalhadas durante a Orogênese Transamazônica (Montalvão \& Tassinari 1984, Sato \& Tassianri 1997, Avelar 2002, Avelar et al. 2003). Na região norte e na fronteira com a Guiana Francesa, os ortognaisses e granitóides são essencialmente relacionados à evolução neoriaciana da Orogênese Transamazônica, como mostram os resultados geocronológicos U-Pb em titanita e zircão e Pb-Pb em zircão (Nogueira et al. 2000, Lafon et al. 2001, Avelar 2002, Lafon et al. 2003). Testemunhos de crosta arqueana são registrados apenas em zircões detríticos $(3,2-2,7 \mathrm{Ga})$ de rochas metassedimentares e zircões herdados $(2,9-2,6 \mathrm{Ga})$ e em idades-modelo $\mathrm{T}_{\mathrm{DM}}$ $(2,75-2,40 \mathrm{Ga})$ de granitóides e ortognaisses paleoproterozóicos (Lafon et al. 2000, Avelar et al. 2001, 2003).

Na região central do Amapá e noroeste do Pará, evidências de crosta continental arqueana foram encontradas, principalmente constituídas por rochas de alto

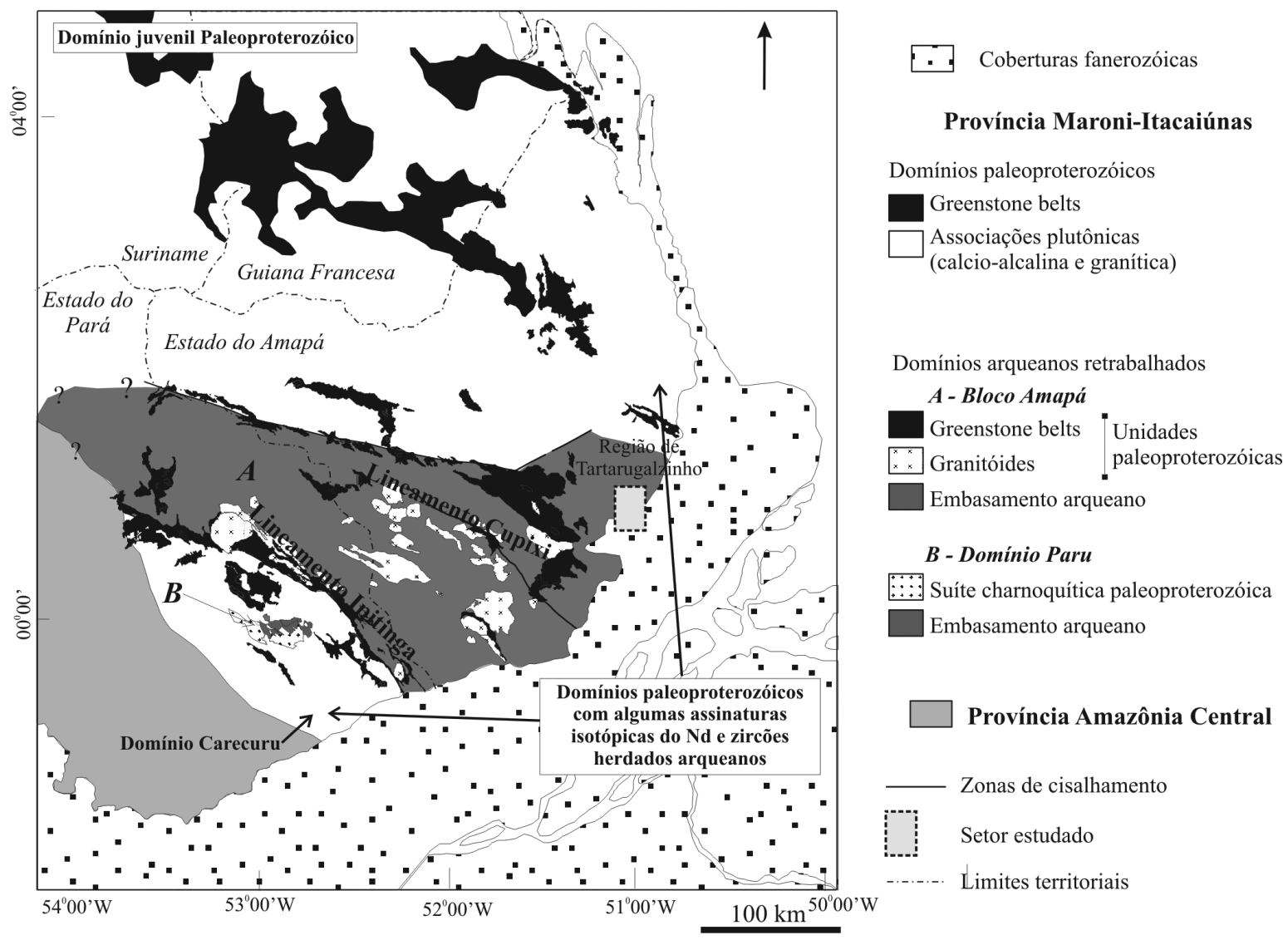

Figura 1 - Mapa do sudeste do Escudo das Guianas mostrando os domínios tectônicos - geocronológicos paleoproterozóicos e arqueanos, segundo Rosa-Costa et al. (2006). A denominação das províncias geocronológicas está de acordo com Tassinari \& Macambira (2004). 
grau metamórfico. Por outro lado, estes núcleos mais antigos, apresentam um forte retrabalhamento metamórfico no Paleoproterozóico (Montalvão \& Tassinari 1984, Tassinari et al. 2000, Pimentel et al 2002, Avelar et al. 2003, Rosa-Costa et al. 2003, 2006). Os dados geocronológicos mais recentes obtidos na porção centro-sul do Amapá e noroeste do Pará levaram à identificação de um bloco continental arqueano denominado de Bloco Amapá, limitado a sul por um arco magmático Transamazônico denominado de domínio Carecuru (Rosa-Costa et al. 2006). O limite norte do Bloco Amapá é marcado por faixas de seqüências metavolcanosedimentares do Grupo Vila Nova (micaxistos, quartzitos e anfibolitos) e granitóides associados na região de Tartarugalzinho, porém a continuação a oeste desse limite ainda não foi bem determinada devido à falta de acesso no campo.

Quadro geológico do bloco Amapá As principais unidades litológicas do Bloco Amapá são formadas por assembléias metamórficas e plutônicas do embasamento arqueano, granitóides e seqüências tipo greenstone belt paleoproterozóicas. (Ricci et al. 2001, RosaCosta et al. 2003, 2006, McReath \& Faraco 2006). O embasamento arqueano é constituído, essencialmente na porção norte do Bloco Amapá, por ortognaisses de fácies anfibolito, localmente migmatizados, enquanto que na parte sul predominam complexos de rochas de alto grau, representados por ortognaisses e rochas metasedimentares granulitizadas, associadas a ortognaisses da transição granulito-anfibolito e gnaisses de fácies anfibolito. Os dados geocronológicos $\mathrm{Pb}-\mathrm{Pb}$ zircão e $\mathrm{Sm}-\mathrm{Nd}$ em rocha total, indicam que as atividades magmáticas ocorreram principalmente nos períodos de 2,85-2,79 Ga e 2,66-2,60 Ga, porém com registros de episódios desde 3,3 Ga. Um período prolongado de formação de crosta juvenil ocorreu em torno de 3,292,83 Ga, enquanto que durante o Neoarqueano, predominaram processos de retrabalhamento crustal da crosta,mesoarqueana pré-existente (Montalvão \& Tassinari 1984, Sato \& Tassinari 1997, Lafon et al. 1998, Tassinari et al. 2000, Avelar 2002, Avelar et al. 2003, Rosa-Costa et al. 2003, 2006). Durante a Orogênese Transamazônica, processos de retrabalhamento crustal também predominaram com participação limitada de acresção juvenil em torno de 2,3 Ga. Vários episódios de magmatismo granítico foram registrados em 2,22, 2,18 e 2,05-2,03 Ga. A maioria dos valores de $\varepsilon_{\mathrm{Nd}}$ e as idades-modelo $\mathrm{T}_{\mathrm{DM}}$ indica uma origem desse magmatismo por mistura entre magmas paleoproterozóicos e componentes arqueanos. Seqüências supra-crustais metarmofisadas na fácies anfibolito (Grupo Vila Nova) formam cinturões paleoproterozóicos, sobretudo nas bordas sul e norte do Bloco Amapá (McReath \& Faraco 2006). Dados Sm-Nd obtidos em rochas anfibolíticas e actinolita xistos (Greenstone Belt Ipitinga), definindo uma idade de $2267 \pm 66 \mathrm{Ma}$ (McReath \& Faraco, 2006) reforçam a idade paleoproterozóica dessas rochas e permitem correlacionar as unidades do Grupo Vila Nova com aquelas do Grupo Paramacá, na Guiana Francesa, (Gruau et al. 1985, Vanderhaege et al. 1998, Delor et al. 2003a) e do Grupo Barama-Mazaruni, na República da Guiana (Gibbs \& Olszewski 1982). Entretanto, essas seqüências do Grupo Vila Nova no Bloco Amapá parecem ter se formado em um contexto geodinâmico diferente das outras seqüências greenstone da PMI já que apresentam assinaturas geoquímicas de margem passiva ou bacia oceânica e idades um pouco mais antigas de 2,27 Ga em relação às idades de 2,19-2,13 Ga encontradas para os terrenos TTG-greenstones da Guiana Francesa, (McReath \& Faraco 2006). Finalmente, uma granitogênese pós-Transamazônica, de idade estateriana e provavelmente anorogênica foi identificada no Bloco Amapá com idade entre 1,75 e 1,71 Ga (Granito Waiãpi e Granodiorito Falsino; Vasquez \& Lafon 2001, CPRM 2004).

O Complexo granulítico de Tartarugal Grande No sudeste do Escudo das Guianas, complexos granulíticos são conhecidos no noroeste do Suriname (Bakhuis Moutains) e no Bloco Amapá (Tassinari et al. 2000, Delor et al. 2003b). No Bloco Amapá, Scarpelli (1969) e João et al. (1979) identificaram faixas granulíticas na região de Tartarugal Grande e mais a oeste, ao longo do rio Falsino. São granulitos predominantemente félsicos com granulitos máficos subordinados. Essas faixas de rochas granulíticas com direção NW foram incluídas no Cinturão Granulítico Tumucumaque - CGT (Lima et al. 1982). Hasui et al. (1984) e Costa \& Hasui (1997), baseados em dados geofísicos, propuseram a existência de dois cinturões granulíticos denominados de Cinturão Jarí, na divisa entre os estados do Pará e Amapá, e de Cinturão Amapá, no sul do Estado do Amapá. Lima et al. (1991) redefiniram o CGT, adotando a designação de Suíte Metamórfica Ananaí-Tartarugal Grande e consideraram o posicionamento estratigráfico dessas rochas como sendo idêntico ao dos ortognaisses do embasamento arqueano, acrescentando ainda, que, tais rochas seriam de nível intermediário, mesozonal, e aquelas da Suíte Metamórfica Ananaí-Tartarugal Grande de nível profundo, catazonal. No sudeste do Amapá, na região de fronteira com o Pará, Carvalho et al. (2001) incluíram, no Cinturão Jari, as rochas de alto grau metamórfico em diversos complexos (Complexos Baixo Amapari, Jari-Guaribas, Iratapuru e Ananaí). Rosa-Costa et al. (2001, 2003, 2006) determinaram idades $\mathrm{Pb}-\mathrm{Pb}$ em zircões de $2790 \pm 15 \mathrm{Ma}, 2788 \pm 2 \mathrm{Ma}$ e 2790 \pm 8 Ma para os protólitos dos gnaisses enderbíticos do Complexo Jari-Guaribas e de $2582 \pm 6$ Ma para aqueles dos gnaisses enderbíticos do Complexo Ananaí.

$\mathrm{Na}$ região de Tartarugal Grande, como nas outras áreas de ocorrência as rochas granulíticas félsicas predominam sobre as rochas máficas e metassedimentares. João \& Marinho (1982) estabeleceram a litologia do complexo granulítico e propuseram um quadro estratigráfico para a região. A unidade mais antiga é constituída pela Suíte Metamórfica Ananaí, que inclui a unidade Piriclasito Mutum (composto principalmente por hiperstênio-piroclásio granulitos) e algumas ocorrências de quartzitos bandados com leitos ferríferos. As rochas granulíticas félsicas foram englobadas na Suíte Meta- 
mórfica Tartarugal Grande, constituídas por granulitos de composição charno-enderbítica denominados de granulitos félsicos indivisos. Neles, foram individualizados o granulito charnoquítico Cuatá e o enderbítico Cobra. Junto a esses tipos, kinzigitos foram também descritos, porém de ocorrência bastante restrita. Ainda de acordo com João \& Marinho (1982), a paragênese mineral dos granulitos enderbíticos e charnoquíticos possibilitam caracterizar um regime de pressão intermediária.

Lima et al. (1982) e João \& Marinho (1982) definiram, para um conjunto de rochas de composição charnoenderbítica uma isócrona $\mathrm{Rb}-\mathrm{Sr}$ com idade de $2450 \pm 74$ Ma e $\mathrm{I}_{\mathrm{Sr}}$ de 0,7063. Uma amostra desse conjunto, tratada isoladamente, definiu uma idade de $3,34 \mathrm{Ga}$ com $\mathrm{I}_{\mathrm{Sr}}$ de 0,705 . Montalvão \& Tassinari (1984) recalcularam os dados isotópicos apresentados para as amostras anteriormente citadas e obtiveram uma idade de $2674 \mathrm{Ma}$, com $I_{S r}$ de 0,7045 . Segundo esses autores, o valor da razão inicial sugere de que tais rochas foram formadas a partir de uma fonte mista, com material retrabalhado do manto e da crosta. Dados $\mathrm{Pb}-\mathrm{Pb}$ em zircão desses mesmos granulitos félsicos da região de Tartarugal Grande forneceram uma idade mínima em torno de 2,6 Ga (Lafon et al. 1998, Avelar et al. 2001, 2003). As idades-modelo $\left(\mathrm{T}_{\mathrm{DM}}\right)$ para essas rochas situaram-se no intervalo de 2,70 Ga a 3,2 Ga (Avelar et al. 2001, 2003). Um plúton charnoquítico da mesma área apresentou uma idade $\mathrm{Pb}-\mathrm{Pb}$ em zircão de $2053 \pm 1 \mathrm{Ma}$ (Avelar 2002). As relações entre o metamorfismo granulítico regional e o magmatismo charnoquítico não foram bem estabelecidas, entretanto, sugere-se que eles sejam contemporâneos, admitindo, portanto, uma idade tardi-Transamazônica também para o episódio de alto grau. Recentemente, Faraco et al. (2006) divulgaram novos resultados para charnoquitos e enderbitos de Tartarugal Grande, com idades $\mathrm{Pb}-\mathrm{Pb}$ em zircão de 2,02-1,90 Ga e $\mathrm{T}_{\mathrm{DM}}(\mathrm{Nd})$ de 3,05-2,64 Ga, sugerindo que o episódio magmático ocorreu também durante o Orisiriano.

\section{DESCRIÇÃODO PROCEDIMENTOEXPERIMEN-}

TAL As amostras de granulitos de Tartarugal Grande, estudadas nesse trabalho, foram processadas segundo o procedimento padrão do Pará-Iso que inclui trituração, pulverização, quarteamento e peneiramento a uma granulometria de 80 mesh, já descrito em trabalhos anteriores (Avelar, 2002). No caso do granulito BA14A e BA14B, rocha total e concentrados de granadas foram preparados no laboratório do BRGM - Serviço Geológico Francês, em Orleans, na França, e a purificação desses concentrados foi realizada por triagem manual sob lupa binocular após trituração das amostras com gral de ágata.

Dissolução das amostras em forno micro-ondas: $\mathrm{O}$ modelo de bomba utilizado para digestão ácida das amostras é manufaturado em teflon PTFE (marca Bolhender ${ }^{\circledR}$, modelo $B O L A$ ). Pode ser utilizado tanto para dissolução em forno de microondas como para dissolução em estufa. A bomba possui cadinho interno com volume de $20 \mathrm{~mL}$, e tem um limite de quantidade de amostra de $250 \mathrm{mg}$ e volume de ácido de $4 \mathrm{~mL}$, para temperatura e pressão máximas de $150{ }^{\circ} \mathrm{C}$ e 20 bars, respectivamente.

Uma quantidade de 50 a $100 \mathrm{mg}$ de amostra de rocha ou de concentrado de minerais é introduzida no cadinho interno da bomba de dissolução junto com

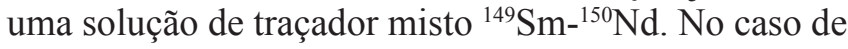
concentrado de minerais, os mesmos são previamente pulverizados em gral de ágata. Uma primeira etapa de dissolução é realizada com $1 \mathrm{~mL}$ de $\mathrm{HNO}_{3}{ }^{* *}$ (bidestilado) concentrado e $3 \mathrm{~mL}$ de $\mathrm{HF}^{* *}$ concentrado, no forno de microondas por 36 minutos a uma potência $400 \mathrm{~W}$.

Após evaporação da solução em uma chapa aquecedora a $100^{\circ} \mathrm{C}$, uma segunda etapa de dissolução é realizada com a mesma mistura de ácidos e com a mesma rotina de aquecimento no forno de microondas. Após resfriamento e evaporação da solução, $3 \mathrm{~mL}$ de $\mathrm{HCl}^{* *} 6 \mathrm{~N}$ são adicionados e a bomba é introduzida no forno de microondas para a terceira etapa de dissolução nas mesmas condições de aquecimento.

Após evaporação a $100^{\circ} \mathrm{C}, 3 \mathrm{~mL}$ de $\mathrm{HCl}^{* *} 2 \mathrm{~N}$ são introduzidos e evaporados até a secura, o resíduo sólido é dissolvido com $1 \mathrm{~mL}$ de $\mathrm{HCl}^{* *} 2 \mathrm{~N}$ e a solução é centrifugada por 20 minutos. Uma alíquota de $0,5 \mathrm{~mL}$ desta solução é retirada e evaporada a $100^{\circ} \mathrm{C}$ e novamente dissolvida com $100 \mu \mathrm{L}$ de $\mathrm{HCl}^{* *} 2 \mathrm{~N}$ para ser em seguida introduzida na coluna de separação.

Separação dos elementos Sm e Nd A separação dos elementos terras raras (ETRs) dos outros elementos é realizada em coluna de teflon com $5 \mathrm{~mm}$ de diâmetro e $25 \mathrm{~cm}$ de altura, preenchida com $2 \mathrm{~mL}$ de resina catiônica Biorad Dowex 50W-X8, a qual é limpa com introdução de $15 \mathrm{~mL}$ de $\mathrm{HCl}^{* *} 6 \mathrm{~N}$, seguida de uma retrolavagem com $10 \mathrm{~mL} \mathrm{HCl} * * 2 \mathrm{~N}$. Posteriormente, a resina é condicionada com $5 \mathrm{~mL}$ de $\mathrm{HCl}^{* *} 2 \mathrm{~N}$. A alíquota de $0,5 \mathrm{~mL}$ de amostra, previamente dissolvida em $100 \mu \mathrm{L}$ de $\mathrm{HCl}^{* *} 2 \mathrm{~N}$, é introduzida na coluna, seguida de $17,5 \mathrm{~mL}$ de $\mathrm{HCl}^{* *} 2 \mathrm{~N}$. Para a eluição dos ETRs, foram acrescentados $5 \mathrm{~mL}$ de $\mathrm{HNO}_{3}{ }^{* *} 3 \mathrm{~N}$ e os ETRs são coletados na fração seguinte de $6 \mathrm{~mL}$ de $\mathrm{HNO}_{3}^{* *} 3 \mathrm{~N}$. A solução coletada é evaporada e a amostra é dissolvida novamente com $100 \mu \mathrm{L}$ de uma mistura $\mathrm{HNO}_{3}{ }^{* *} 7 \mathrm{~N}+$ Metanol** concentrado, para a separação dos elementos Sm e Nd na segunda etapa do procedimento de separação química.

Os elementos Sm e Nd são separados dos outros ETRs e purificados por cromatografia de troca iônica em coluna de teflon de diâmetro e altura, similar à coluna precedente, preenchida com $2 \mathrm{~mL}$ de resina aniônica Dowex AG1-X4. A resina passa por uma limpeza com $10 \mathrm{~mL}$ de $\mathrm{HNO}_{3}{ }^{* *} 1 \mathrm{~N}$ através de retrolavagem, e a limpeza é finalizada com $5 \mathrm{~mL}$ de $\mathrm{HNO}_{3}{ }^{* *} 1 \mathrm{~N}$. O condicionamento da resina é realizado com a introdução de $10 \mathrm{~mL}$ de uma mistura $\mathrm{HNO}_{3}^{* *} 7 \mathrm{~N}+$ Metanol** concentrado na proporção 4:6. A solução amostra de terras raras é introduzida na coluna e $6,9 \mathrm{~mL}$ da mistura $\mathrm{HNO}_{3} * * 7 \mathrm{~N}+$ Metanol** concentrado são acrescentados e descartados. A fração de Sm é coletada em cadinho de teflon com $4 \mathrm{~mL}$ de $\mathrm{HNO}_{3}{ }^{* *} 7 \mathrm{~N}+$ Metanol** concentrado. Posteriormente são adicionados e descartados mais $4 \mathrm{~mL}$ da mistura ácida e a eluição da fração 
concentrada de $\mathrm{Nd}$ é realizada com a adição de $7 \mathrm{~mL}$ de $\mathrm{HNO}_{3}^{* *} 7 \mathrm{~N}+$ Metanol** concentrado. Após esta coleta, $5 \mathrm{~mL}$ de $\mathrm{HNO}_{3}^{* *} 1 \mathrm{~N}$ são adicionados na coluna para a limpeza da resina. As frações concentradas de $\mathrm{Sm}$ e $\mathrm{Nd}$ coletadas são evaporadas. Em seguida, $1 \mathrm{~mL}$ de $\mathrm{HNO}_{3}^{* *}$ concentrado é adicionado em cada fração e as soluçõ̃es são novamente evaporadas.

Análises isotópicas no espectrômetro de massa Para a análise isotópica de $\mathrm{Sm}$ e $\mathrm{Nd}$ no espectrômetro de massa são utilizados arranjos de filamentos duplos tântalo (evaporação) - rênio (ionização). O depósito é realizado com 1 $\mu \mathrm{L}$ de $\mathrm{H}_{3} \mathrm{PO}_{4} 0,1 \mathrm{M}$ e mais $1 \mu \mathrm{L}$ de $\mathrm{HNO}_{3}^{* *} 1 \mathrm{~N}$.

As análises isotópicas de $\mathrm{Sm}$ e $\mathrm{Nd}$ são realizadas em modo estático em um espectrômetro de massa de termo-ionização da marca FINNIGAN modelo MAT 262, equipado com um sistema de multicoleção, com sete coletores de Faraday. A determinação da composição isotópica do $\mathrm{Nd}$ é realizada com a análise de dez blocos sucessivos de dez medidas isotópicas, permitindo a obtenção das razões ${ }^{142} \mathrm{Nd} /{ }^{144} \mathrm{Nd},{ }^{143} \mathrm{Nd} /{ }^{144} \mathrm{Nd}$, ${ }^{145} \mathrm{Nd} /{ }^{144} \mathrm{Nd},{ }^{146} \mathrm{Nd} /{ }^{144} \mathrm{Nd},{ }^{147} \mathrm{Sm} /{ }^{144} \mathrm{Nd}$ e ${ }^{150} \mathrm{Nd} /{ }^{144} \mathrm{Nd}$. A razão ${ }^{146} \mathrm{Nd} /{ }^{144} \mathrm{Nd}$ igual a 0,7219 é utilizada para a normalização das razões. Para o elemento Sm, a compo- sição isotópica é determinada com a análise de cinco blocos de dez medidas dos isótopos ${ }^{147} \mathrm{Sm},{ }^{149} \mathrm{Sm},{ }^{152} \mathrm{Sm}$, ${ }^{154} \mathrm{Sm} \mathrm{e}{ }^{155} \mathrm{Gd} .{ }^{152} \mathrm{Sm} /{ }^{147} \mathrm{Sm}$ é a razão de referência para corrigir o fracionamento e ${ }^{155} \mathrm{Gd} /{ }^{147} \mathrm{Sm}$ corrige a interferência do gadolínio.

Controle dos "brancos" experimentais, aferição e controle analítico O "branco" total do procedimento experimental está abaixo de 170 pg de Nd e 80 pg de Sm. Na etapa de separação química dos elementos de $\mathrm{Nd}$ e $\mathrm{Sm}$, os brancos obtidos foram de 60-40 pg para o Nd e 30 pg para o Sm.

Para aferição do método e controle das análises isotópicas no espectrômetro de massa, foram utilizados os padrões BCR-1 (Basalto USGS) e o padrão La Jolla. Os resultados das análises do padrão BCR-1, apresentados na tabela 1 , mostraram valores obtidos de concentrações de $\mathrm{Sm}$ e Nd bastante reprodutíveis. Os valores obtidos para a razão ${ }^{143} \mathrm{Nd} /{ }^{144} \mathrm{Nd}$ oscilaram entre $0,512573 \pm 12(1 \sigma)$ e $0,512669 \pm 10(1 \sigma)$, com valor médio de $0,512622 \pm 28(1 \sigma)$. As médias das concentrações de Nd e Sm foram de 28,58 ppm e 6,56 ppm, respectivamente. Apesar de apresentarem alguns valores um pouco baixo para a razão ${ }^{143} \mathrm{Nd} /{ }^{144} \mathrm{Nd}$ (análises $n^{0} 1$ e 2), os resultados obtidos estão dentro dos valores en-

Tabela 1 - Valores de concentração e composição isotópica do padrão BCR-1, obtidos no Pará-Iso e em outros laboratórios.

\begin{tabular}{l|l|l|l|l}
\hline${ }^{143} \mathrm{Nd} /{ }^{144} \mathrm{Nd}( \pm 1 \delta)$ & $\mathrm{Nd}(\mathrm{ppm})$ & $\mathrm{Sm}(\mathrm{ppm})$ & Equipamento & Referências \\
\hline $0,512596(5)$ & 28,38 & 6,51 & Finnigan MAT 262 & Este trabalho \\
\hline $0,512573(12)$ & 28,78 & 6,60 & Finnigan MAT 262 & Este trabalho \\
\hline $0,512657(18)$ & 28,58 & 6,62 & Finnigan MAT 262 & Este trabalho \\
\hline $0,512669(10)$ & 28,60 & 6,50 & Finnigan MAT 262 & Este trabalho \\
\hline $0,512634(4)$ & 28,54 & 6,59 & Finnigan MAT 262 & Este trabalho \\
\hline $0,512622(28)$ & 28,58 & 6,56 & Finnigan MAT 262 & Este trabalho (média) \\
\hline $0,512630(3)$ & ni. & ni. & ni. & Maboko \& Nakamura (1995) \\
\hline $0,512653(5)$ & ni. & ni. & Finnigan MAT 261 & Sun et al. (1995) \\
\hline $0,512633(6)$ & $28,84(4)$ & $6,59(1)$ & Finnigan MAT262 & Kröner et al. (1996) \\
\hline $0,512632(2)$ & 28,73 & 6,66 & Finnigan MAT 262 & Gioia \& Pimentel (2000) \\
\hline $0,512631(8)$ & ni. & ni. & Finnigan MAT 261 & Wang et al. (1998) \\
\hline $0,512663(9)$ & 28,45 & 6,487 & Finnigan MAT 261 & Arzamastev et al. (2000) \\
\hline $0,512662(5)$ & ni. & ni. & Finnigan MAT 262 & França et al. (2006) \\
\hline $0,512644(11)$ & 28,75 & 6,57 & Finnigan MAT 261 & Peng et al. (2003) \\
\hline
\end{tabular}

ni: não informado 
contrados em outros laboratórios (Tab. 1), e em particular, com os valores fornecidos pelos outros laboratórios brasileiros (França et al 2006, Gioia 1997).

Os valores obtidos para as razões isotópicas de ${ }^{143} \mathrm{Nd} /{ }^{144} \mathrm{Nd}$ em 13 análises do padrão La Jolla se encontraram no intervalo entre $0,511793 \pm 9$ e 0,511883 \pm 5 , sendo a maioria dos valores acima de 0,5118 . A partir dessas medidas foi calculado um valor médio de ${ }^{143} \mathrm{Nd} /{ }^{144} \mathrm{Nd}$ de $0,511845 \pm 6$ (Tab. 2). Esse valor é considerado satisfatório e garante a exatidão analítica das razões isotópicas do Nd obtidas no Pará-Iso, apesar das análises terem sido realizadas utilizando um filamento de Ta para de evaporação em lugar de um filamento de Re, como na maioria dos outros laboratórios. Na tabela 2, os resultados do Pará-Iso são comparados com os valores publicados em outros trabalhos que realizaram análises em filamento de Re.

GEOCRONOLOGIA Sm-Nd EM ROCHA TOTAL

E GRANADA Duas amostras de rochas granulíticas foram coletadas no mesmo afloramento, na margem da BR156, alguns quilômetros a norte da cidade de Ferreira Gomes $\left(01^{\circ} 03^{\prime} 16^{\prime \prime} \mathrm{S} ; 51^{\circ} 05^{\prime} 19^{\prime \prime} \mathrm{W}\right.$ - Fig. 2). A amostra CA13A, mostra um arranjo mineral que caracteriza uma textura granoblástica, de granulação média e coloração cinza-clara. A amostra é um granulito félsico com granada de composição granítica, constituída essencialmente por K-feldspato (ortoclásio), quartzo, plagioclásio (subordinado), anfibólio, granada e biotita, e por opacos e zircão como acessórios, enquanto clorita e a sericita são secundários. Apresenta textura do tipo granular alotriomórfica a porfiroblástica. A

Tabela 2 - Valores da razão ${ }^{143} \mathrm{Nd} /{ }^{144} \mathrm{Nd}$ do padrão La Jolla, obtidos no Pará-Iso e em outros laboratórios (espectrômetros de massa Finnigan MAT 261 e 262).

\begin{tabular}{|c|c|c|c|}
\hline${ }^{143} \mathrm{Nd} /{ }^{144} \mathrm{Nd}( \pm 1 \delta)$ & Equipamento & Modo & Referências \\
\hline $0,511829(2)$ & Finnigan MAT 262 & Estático & Este trabalho \\
\hline $0,511835(11)$ & Finnigan MAT 262 & Estático & Este trabalho \\
\hline * 0,511749 (20) & Finnigan MAT 262 & Estático & Este trabalho \\
\hline $0,511793(9)$ & Finnigan MAT 262 & Estático & Este trabalho \\
\hline $0,511806(5)$ & Finnigan MAT 262 & Estático & Este trabalho \\
\hline $0,511860(4)$ & Finnigan MAT 262 & Estático & Este trabalho \\
\hline $0,511847(4)$ & Finnigan MAT 262 & Estático & Este trabalho \\
\hline $0,511883(5)$ & Finnigan MAT 262 & Estático & Este trabalho \\
\hline $0,511854(7)$ & Finnigan MAT 262 & Estático & Este trabalho \\
\hline $0,511877(6)$ & Finnigan MAT 262 & Estático & Este trabalho \\
\hline $0,511861(4)$ & Finnigan MAT 262 & Estático & Este trabalho \\
\hline $0,511849(4)$ & Finnigan MAT 262 & Estático & Este trabalho \\
\hline $0,511862(8)$ & Finnigan MAT 262 & Estático & Este trabalho \\
\hline $0,511830(15)$ & Finnigan MAT 262 & Estático & Este trabalho \\
\hline $0,511845(6)$ & Finnigan MAT 262 & Estático & Este trabalho (média) \\
\hline $0,511872(2)$ & Finnigan MAT 261 & Estático & Zhao \& McCulloch (1995) \\
\hline $0,511854(11)$ & Finnigan MAT 262 & Semi-dinâmico & Chavagnac \& Jahn (1996) \\
\hline 0,511845 (ni) & Finnigan MAT 262 & ni. & Thöni \& Miller (1996) \\
\hline $0,511835(14)$ & Finnigan MAT 262 & Estático & Gioia \& Pimentel (2000) \\
\hline $0,511848(21)$ & Finnigan MAT 261 & Estático & Jung \& Mezger (2003) \\
\hline $0,511852(15)$ & Finnigan MAT 261 & Dinâmico & Mayer et al. (2004) \\
\hline $0,511847(5)$ & Finnigan MAT 262 & Estático & França et al. (2006) \\
\hline 0,511856 (ni) & VG 54 MICROMASS & ni. & Borba et al. (2006) \\
\hline $0,511846(11)$ & VG Sector & ni. & Stoeser \& Frost (2006) \\
\hline
\end{tabular}

ni: não informado, *: valor não incluído no cálculo da média. 


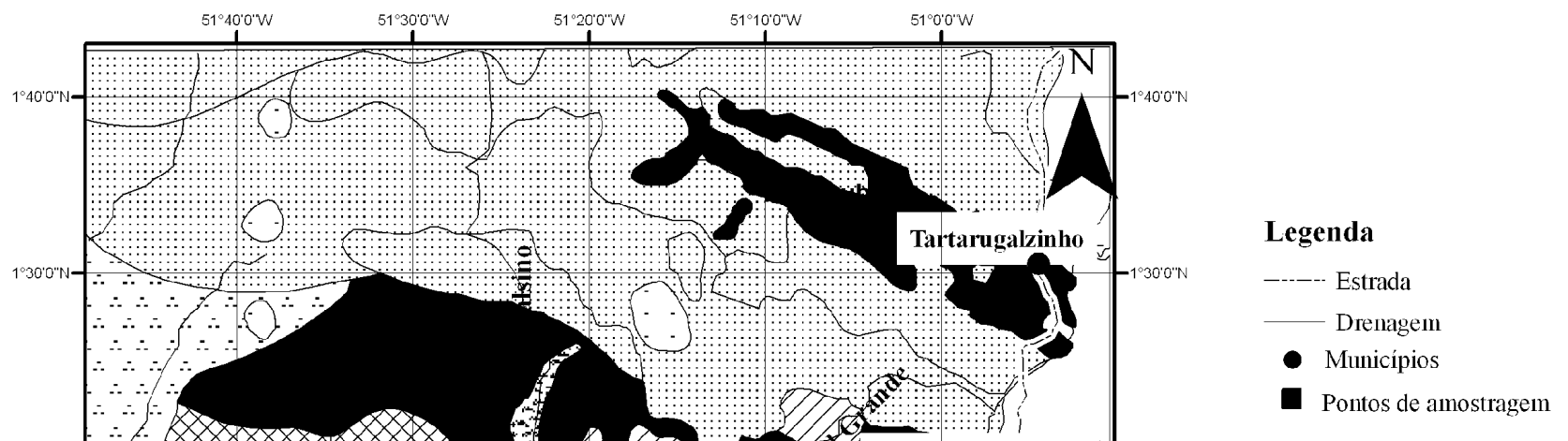

Unidades litológicas
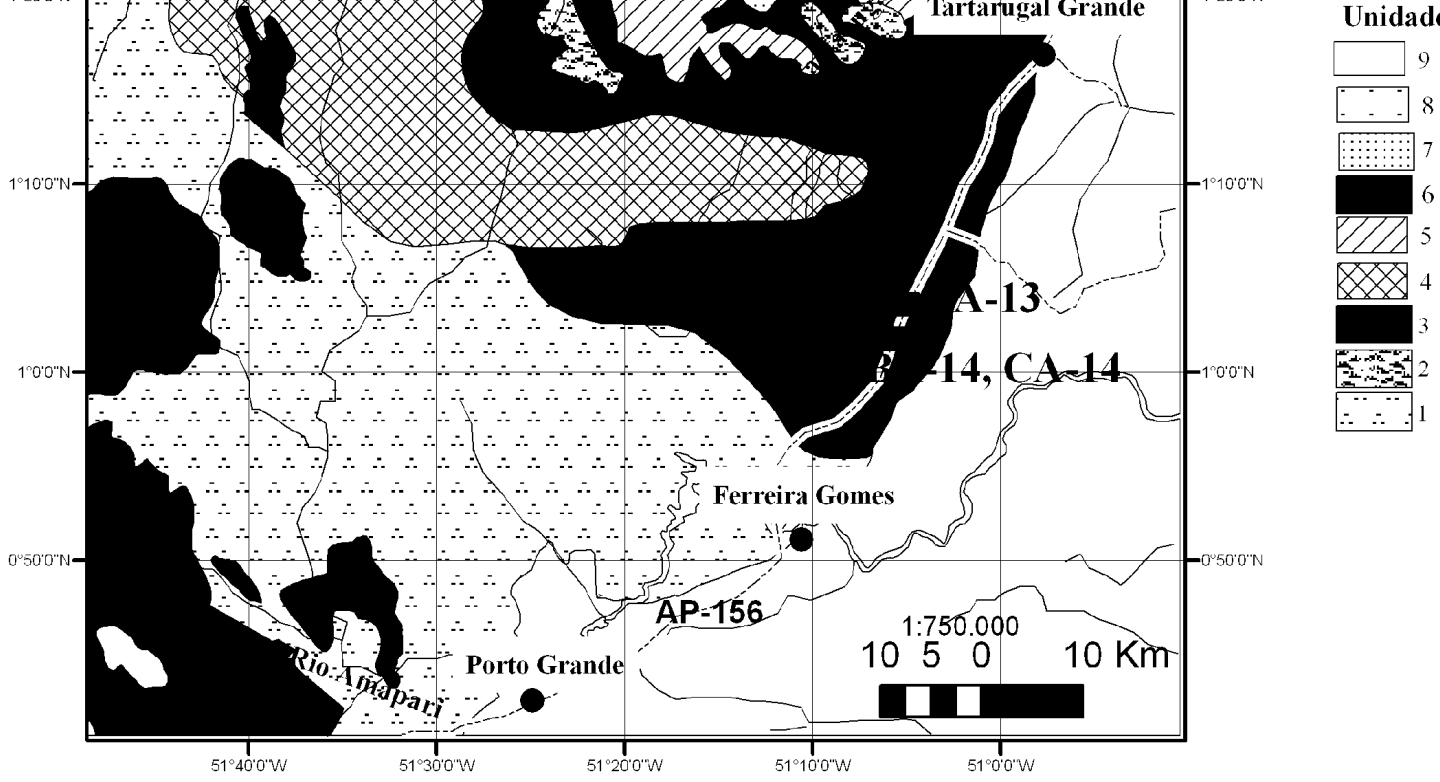

Figura 2 - Mapa geológico da área de Tartarugal Grande segundo João \& Marinho (1982) e CPRM (2004). 1. Gnaisses arqueanos de composição granodiorítica a tonalítica; 2. Granulitos máficos (Piriclasito Mutum); 3. Granulitos félsicos indivisos; 4. Granulitos enderbíticos (Enderbito Cobra); 5. Granulitos charnoquíticos (Charnoquito Cuatá); 6. Seqüência tipo greenstones belt (Grupo Vila Nova);7. Granitóides neoriacianos; 8. Granitóides estaterianos (Granodiorito Falsino); 9. Coberturas fanerozóicas (Grupo Barreiras e depósitos aluvionários).

granada, tipo almandina, constitui porfiroblastos com fraturas freqüentemente preenchidas por biotita. A outra amostra (amostra CA13B), de composição charnoquítica, é uma rocha levemente anisotrópica, de textura granular porfirítica e granulação média, com fenocristais esbranquiçados de K-feldspato, dispersos numa matriz cinza escuro. A rocha contém predominantemente K-feldspato (ortoclásio e microclina), quartzo, ortopiroxênio e biotita. Observa-se um processo de transformação da biotita em ortopiroxênio (biotita + quartzo ${ }^{\circledR} \mathrm{K}$-feldspato + ortopiroxênio), resultante da transformação metamórfica, por elevação de temperatura, dentro da fácies granulito. Datações $\mathrm{Pb}-\mathrm{Pb}$ em zircão dessas duas amostras forneceram idades espalhadas em um intervalo de 2,58 a 2,60 Ga, consideradas como idades mínimas de formação dos protólitos ígneos dos granulitos (Avelar et al. 2003).

Cerca de $3 \mathrm{~km}$ a sul do ponto anterior $\left(01^{\circ} 01^{\prime}\right.$ $45,6^{\prime \prime S}$ e $51^{\circ} 05^{\prime} 30^{\prime}$ W- Fig. 2), também na margem da BR156, foi coletada uma rocha granulítica (amostra CA14A), constituída predominantemente por K-feldspato (microclina + ortoclásio), quartzo e plagioclásio, porém sem a presença de piroxênio. Os minerais acessórios são zircão e opacos; enquanto que sericita é secundária. Nesse mesmo afloramento foram coletadas outras amostras de rocha granulítica félsica (amostras CA14B, BA14A e BA14B), de granulação fina a média, que apresentam uma foliação marcante $\mathrm{N} 150^{\circ}$ subhorizontal e contêm freqüentes veios sub-horizontais de espessura centimétrico a decimétrico. Tratam-se de rochas de textura granoblástica, de granulação média e coloração cinza-clara A assembléia mineralogíca é constituída por K-feldspato, quartzo, plagiocásio e granada abundante. Os veios sub-horizontais constituem mobilisados félsicos originados por fusão in situ da rocha granulítico. Têm textura granular e são constituídos por ortoclásio pertítico, quartzo, granada e biotita, enquanto que zircâo e minerais opacos são 
acessórios e sericita é secundária. A amostra BA14A representa a rocha granulítica não fundida, enquanto que as amostras BA14B e CA14B correspondem ao veio, produto de fusão in situ da rocha representada pela amostra BA14A.

RESULTADOS ANALÍTICOS As análises das amostras de rocha total CA13A, CA14A e CA14B e dos concentrados de granada (CA13A, BA14A e BA14B), foram duplicatas no laboratório de geocronologia da UnB. Os dados das amostras de rocha total BA14A e BA14B foram obtidos no Laboratório de Geocronologia do BRGM, Serviço Geológico Francês. Os resultados geocronológicos são fornecidos com desvio de um $\sigma$. Os dados analíticos são apresentados na tabela 3 . Os cálculos de isócrona rocha total granada (amostras CA13A, BA14A e BA14B) foram realizados com auxílio do programa ISOPLOT (Ludwig 2000) e as idades-modelo $\mathrm{T}_{\mathrm{DM}}$ foram determinadas com base no modelo de evolução do Nd no manto empobrecido de DePaolo (1981).

Isócronas RT - granada A isócrona definida pela amostra CA13A (RT- granada) forneceu idade de 2017 \pm 12 Ma no Pará-Iso e de $2037 \pm 8,4$ Ma na UnB (Fig. 3A). A idade obtida no Pará-Iso foi menor que a idade fornecida pela UnB, porém os resultados são similares dentro dos intervalos dos erros analíticos. No caso da amostra BA14A, as idades obtidas pela isócrona RTgranada (Fig. 3B). foram de 1981,6 $\pm 2,8 \mathrm{Ma}$ (Pará-Iso) e $1988 \pm 11 \mathrm{Ma}(\mathrm{UnB})$, não tendo portanto diferença entre as idades. Para a amostra BA14B, obteve-se isócronas RT - granada (Fig. 3C) que forneceram idades de $2018 \pm 2,3 \mathrm{Ma}$ (Pará-Iso) e $2013 \pm 15 \mathrm{Ma}$ (UnB), as quais são estatisticamente similares, dentro dos erros.

Para todas as amostras, os resultados isotópicos das rochas totais foram bastante similares entre os dois laboratórios, porém com diferenças que excedem um pouco o desvio analítico no caso da amostra CA13A. As concentrações de $\mathrm{Sm}$ e $\mathrm{Nd}$ foram similares em todas as amostras.

As duas outras amostras de rocha total de granulitos da mesma área, analisadas no Pará-Iso e na UnB para a obtenção de idade modelo (CA14A e CA14B), novamente apresentaram teores de $\mathrm{Sm}$ e Nd similares nos dois laboratórios. As razões isotópicas do $\mathrm{Nd}$ foram um pouco diferentes, como no caso da amostra CA13A.

Os concentrados de granada apresentaram diferenças significativas de concentrações de $\mathrm{Sm}$ e $\mathrm{Nd}$ e de composição isotópica quando analisados no Pará-Iso e na UnB, porém sem incidência sobre as idades. No caso da granada da amostra BA14A, as razões ${ }^{147} \mathrm{Sm} /{ }^{144} \mathrm{Nd}$ foram de 0,72 no Pará-Iso e de 0,43 na UnB, com idades similares RT-granada de $1982 \mathrm{Ma}$ e $1988 \mathrm{Ma}$, respectivamente. Isto indica que há variações de composição química na granada, mas que o sistema $\mathrm{Sm}-\mathrm{Nd}$ permaneceu em equilíbrio isotópico. Essa situação se repete no caso das granadas da amostra BA14B onde as razões ${ }^{147} \mathrm{Sm} /{ }^{144} \mathrm{Nd}$ foram de 1,25 no Pará-Iso e de 0,88 na UnB e as respectivas idades RT-granada de $2018 \mathrm{Ma}$ e $2013 \mathrm{Ma}$.

Sendo assim, o fato das análises em rocha total

Tabela 3 - Resultados analíticos Sm-Nd em amostras de granulito félsico rocha total e granada.

\begin{tabular}{|c|c|c|c|c|c|c|c|}
\hline Amostra & Laboratório & $\mathrm{Sm}(\mathrm{ppm})$ & $\mathrm{Nd}(\mathrm{ppm})$ & ${ }^{147} \mathrm{Sm} /{ }^{144} \mathrm{Nd}( \pm 1 \sigma)$ & ${ }^{143} \mathrm{Nd} /{ }^{144} \mathrm{Nd}( \pm 1 \sigma)$ & $\varepsilon_{\mathrm{Nd}}(2,6 \mathrm{Ga})$ & $\mathrm{T}_{\mathrm{DM}}(\mathrm{Ga})$ \\
\hline CA13A Rocha Total & Pará-Iso & 4,55 & 25,20 & $0,10917(10)$ & $0,510914(04)$ & $-4,63$ & 3,15 \\
\hline CA13A Rocha Total & UnB & 4,62 & 25,23 & $0,1106(11)$ & $0,510834(08)$ & $-6,68$ & 3,32 \\
\hline CA13B Rocha Total & Pará-Iso & 3,36 & 25,15 & $0,08070(15)$ & $0,510530(12)$ & $-2,66$ & 2,91 \\
\hline CA13B Rocha Total & UnB & 3,28 & 24,72 & $0,0803(08)$ & $0,510526(18)$ & $-2,61$ & 2,90 \\
\hline CA14A Rocha Total & Pará-Iso & 2,94 & 15,28 & $0,11615(09)$ & $0,511276(16)$ & 0,59 & 2,79 \\
\hline CA14A Rocha Total & $\mathrm{UnB}$ & 3,36 & 17,45 & $0,1164(11)$ & $0,511309(15)$ & 0,94 & 2,74 \\
\hline BA14A Rocha Total & BRGM & 1,93 & 14,43 & $0,080991(15)$ & $0,510542(05)$ & $-11,23$ & 2,90 \\
\hline CA14B Rocha Total & Pará-Iso & 1,54 & 11,04 & $0,08443(15)$ & $0,510650(13)$ & $-10,00$ & 2,85 \\
\hline CA14B Rocha Total & UnB & 1,60 & 11,43 & $0,0844(08)$ & $0,510566(13)$ & $-2,87$ & 2,95 \\
\hline BA14B Rocha Total & BRGM & 0,60 & 4,84 & $0,074979(12)$ & $0,510465(03)$ & $-11,18$ & 2,86 \\
\hline CA13A Granada & Pará-Iso & 9,89 & 8,11 & $0,73716(02)$ & $0,519253(17)$ & & \\
\hline CA13A Granada & $\mathrm{UnB}$ & 11,14 & 10,74 & $0,6269(62)$ & $0,517758(27)$ & & \\
\hline BA14A Granada & Pará-Iso & 5,83 & 4,88 & $0,72194(15)$ & $0,518902(11)$ & & \\
\hline BA14A Granada & $\mathrm{UnB}$ & 7,52 & 10,49 & $0,4331(43)$ & $0,515150(24)$ & & \\
\hline BA14B Granada & Pará-Iso & 4,63 & 2,23 & $1,25243(77)$ & $0,526106(15)$ & & \\
\hline BA14B Granada & UnB & 5,04 & 3,47 & $0,8796(88)$ & $0,521126(80)$ & & \\
\hline
\end{tabular}


realizadas na UnB e no Pará-Iso serem geralmente reprodutíveis ou das pequenas diferenças de idades não terem caráter sistemático, bem como o fato das diferenças maiores serem observadas somente nas amostras de granada, novamente sem caráter sistemático, indicam que a origem dessas diferenças não é analítica e sim geológica.

Isócronas em RT Todas as amostras de rocha total foram também lançadas em um diagrama isocrônico porém não foi possível estabelecer um alinhamento. A tentativa de cálculo da isócrona forneceu um valor de $2666 \pm 960$ Ma com MSWD = 68 (Fig. 4a).Esse resultado não tem significado geológico e parece ser um valor intermediário, entre dois alinhamentos distintos, um definindo um valor de $1965 \pm 110 \mathrm{Ma}(\mathrm{MSWD}=0,11)$ com as amostras (CA13A, CA13B, BA14A e BA14B) e outro com valor de $2988 \pm 97 \mathrm{Ma}$ com as amostras CA14A e CA14B (Fig. 4b).

Idades-modelo $\mathbf{T}_{\mathbf{D M}}$ As idades-modelo $\mathrm{T}_{\mathrm{DM}}$ e retas de evolução da razão isotópica do Nd para as amostras de rocha total são apresentadas na figura 5. Os valores de $\varepsilon_{\mathrm{Nd}(\mathrm{T})}$ foram calculados para uma idade de 2,6 Ga. A amostra de granulito CA13A, indicou idades modelo $\mathrm{T}_{\mathrm{DM}}$ de $3,15 \mathrm{Ga}$ e 3,32 Ga enquanto que a amostra CA13B forneceu idades modelo de 2,90-2,91 Ga, um pouco menor em relação à CA13A. Para essas amostras, os valores de $\varepsilon_{\mathrm{Nd}(\mathrm{T})}$ foram de $-6,68$ e -4,63 para a amostra CA13A e -2,66 e -2,61 para a amostra CA13B. As amostras CA14A e CA14B apresentaram idades de 2,74-2,79 Ga e 2,85-2,95 Ga, respectivamente, com valores de $\varepsilon_{\mathrm{Nd}(\mathrm{T})}$ de 0,59 e 0,94 (CA14A) e -10,0 e -2,87 (CA14B). As amostras BA14A e BA14B apresentaram idades-modelo $\mathrm{T}_{\mathrm{DM}}$ e $\varepsilon_{\mathrm{Nd}(\mathrm{T})}$ bastantes similares de 2,90Ga e 2,86 Ga e -11,23 e-11,18, respectivamente.

Discussão e interpretações Os resultados isotópicos obtidos a partir dos pares RT-granada para as amostras de granulitos determinaram um intervalo de idades relativamente restrito de $60 \mathrm{Ma}$ entre 2,04 e 1,98 Ga com um valor médio de $2005 \pm 21 \mathrm{Ma}(2 \sigma)$. As idades das amostras BA14B (2018 $\pm 2,3 \mathrm{Ma})$ e CA13A $(2017 \pm 12$ Ma) são superiores à idade da amostra BA14A (1981,6 $\pm 2,8 \mathrm{Ma}$ ), porém essa diferença pode não ter significado geológico. Como se tratam de isócronas calculadas a partir de dois pontos, os erros fornecidos individualmente por cada isócrona são provavelmente sub-estimados. As variações observadas para as isócronas determinadas em uma mesma amostra indicam variações nas concentrações de ETR das granadas que podem ser explicadas pela heterogeneidade química e isotópica dos grãos e pela presença de micro-inclusões não detectáveis no microscópio ótico. Por exemplo, foram encontrados cristais de monazita na amostra de rocha total BA14A, assim como inclusões desse mineral na granada (Fig. 6). É comum encontrar variações de concentrações de $\mathrm{Sm}$ e $\mathrm{Nd}$ e, conseqüentemente de razão $\mathrm{Sm} / \mathrm{Nd}$ em granada de acordo com o tamanho e a composição química, além da presença das micro-inclusões (Moyes \& Groenewald 1996, Thöni 2002). Sendo assim, as di-

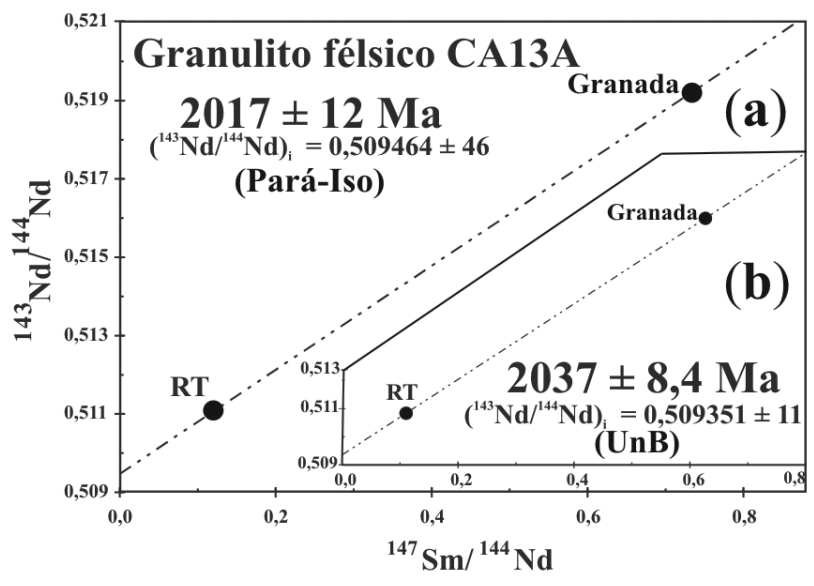

(A)

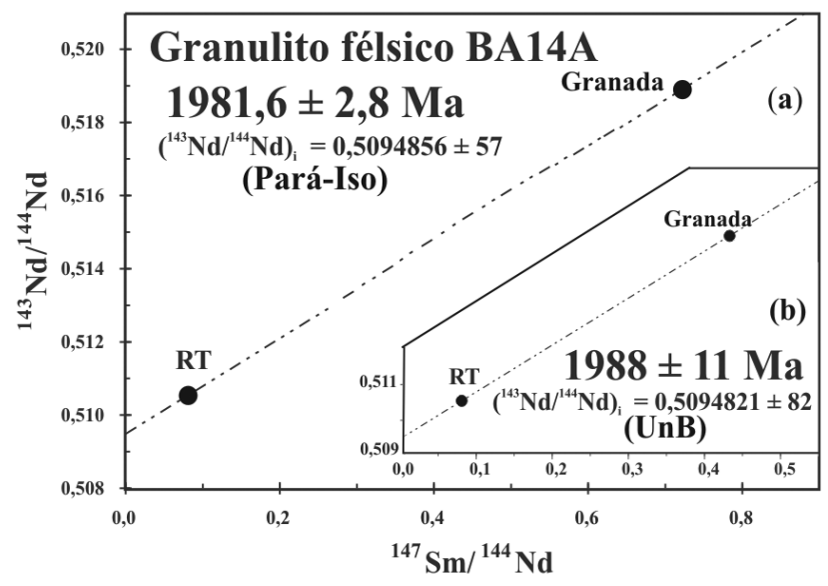

(B)

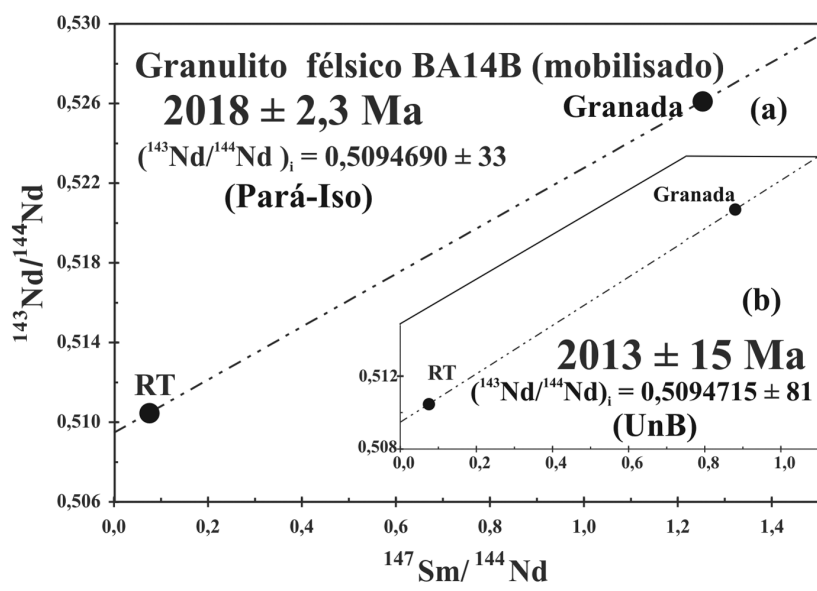

(C)

Figura 3 - Diagramas isocrônicos Sm-Nd para rocha total e granada de granulito félsico. (A) Amostra CA13A; (B) Amostra BA14A; (C) Amostra BA14B. Análises no Pará-Iso (a) e na UnB (b).

ferenças entre as idades da amostra BA14A e as outras duas amostras podem não ser significativas.

Até o momento, os dados $\mathrm{Pb}-\mathrm{Pb}$ em zircão tinham fornecido idades mínimas de 2,6 Ga (Avelar et al. 2003). Idades U-Pb SHRIMP em zircão indicaram 
uma idade de 2,62 Ga, com herança de até 2,94 Ga no caso da amostra BA14A (Lafon et al., em preparação). A idade Rb-Sr em rocha total de 2,45 Ga (João \& Marinho 1982) mostrou que o sistema Rb-Sr não tinha registrado o evento Transamazônico, sugerindo que o evento de alto grau de metamorfismo tinha ocorrido ainda no Arqueano. As idades entre 2,04 e 1,98 Ga são, portanto, as primeiras evidências isotópicas da atuação do evento Transamazônico nessas rochas.

A granada é o mineral mais importante para obtenção de informações geocronológicas para rochas de alto grau metamórfico. Além de apresentar a maior razão $\mathrm{Sm} / \mathrm{Nd}$ entre todos os minerais, é também um mineral importante em muitas reações sendo muito usado para termobarometria e reconstrução quantitativa dos caminhos P-T (Cohen et al. 1988, Mezger et al. 1992). Em certos casos, o sistema Sm-Nd da granada pode preservar a idade de cristalização durante o caminho progressivo do metamorfismo ou datar o paroxismo deste metamorfismo (Burton \& O'Nions 1991). De qualquer forma, a temperatura de fechamento do sistema $\mathrm{Sm}-\mathrm{Nd}$ da granada é sem dúvida uma das mais altas entre os geocronômetros radiométricos, podendo aproximar-se da temperatura de fechamento do cronômetro U-Pb em zircão (Chavagnac \& Jahn 1996). Entretanto, as estimativas de temperatura podem variar de acordo com os autores. Para Mezger et al. (1992), a temperatura de fechamento foi estimada em aproximadamente $600^{\circ} \mathrm{C}$, enquanto que, para outros autores, a mesma foi considerada como $\geq 750^{\circ} \mathrm{C}$ (Jagoutz 1988, Thöni \& Jagoutz 1992, Hensen \& Zhou 1995). As tentativas de determinação da temperatura de fechamento da granada para o sistema Sm-Nd mostram que a mesma não é única e pode variar de acordo com vários parâmetros, tais como o tamanho dos grãos, a composição química, as fases minerais associadas à granada, a presença de fluidos e a velocidade de resfriamento (Burton et al. 1995, Thöni 2002). Mesmo podendo variar de acordo com diversos fatores, a temperatura de fechamento do sistema Sm$\mathrm{Nd}$ da granada é geralmente considerada como superior a $700^{\circ} \mathrm{C}$, o que indica que as idades determinadas nas amostras de granulitos são representativas de um evento de alta temperatura e provavelmente testemunham a época do evento metamórfico de alto grau.

A diferença, da ordem de 10 a $60 \mathrm{Ma}$, entre a idade de formação do plúton charnoquítico e do metmorfismo de alto grau registrado na granada dos granulitos félsicos pode ser explicada pela diferença de temperatura de fechamento dos sistemas isotópicos $\mathrm{U}-\mathrm{Pb}$ em zircão e Sm-Nd em granada. Os dados $\mathrm{Sm}-\mathrm{Nd}$ da granada dos granulitos e $\mathrm{Pb}-\mathrm{Pb}$ em zircão do charnoquito indicam, portanto, uma idade tardi-Transamazônica para o metamorfismo de alto grau e magmatismo associado ocorrido na região central do Amapá. Esse evento pode ser relacionado ao evento de UAT identificado na região noroeste do Suriname, também de idade tardiTransamazônica cujo significado geodinâmico foi interpretado como resultado de processos de "boudinage" tardi-orogenético em escala continental para o sudeste do Escudo das Guianas (Delor et al. 2003b). A interpre-
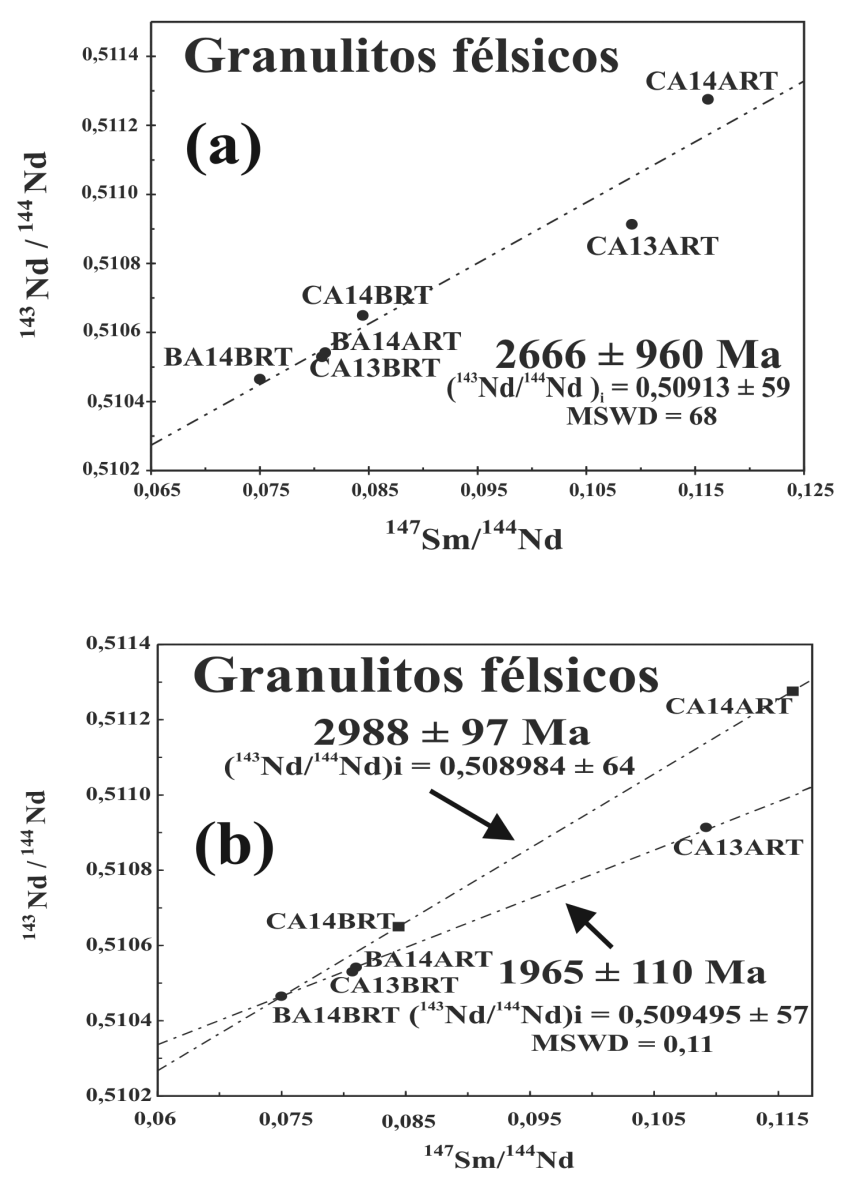

Figura 4 - Diagrama isocrônico das amostras de rocha total de granulito félsico de Tartarugal Grande, com amostras analisadas no Pará-Iso. (a) alinhamento com todas as amostras, (b) alinhamento com idade arqueana e com idade paleoproterozóica.

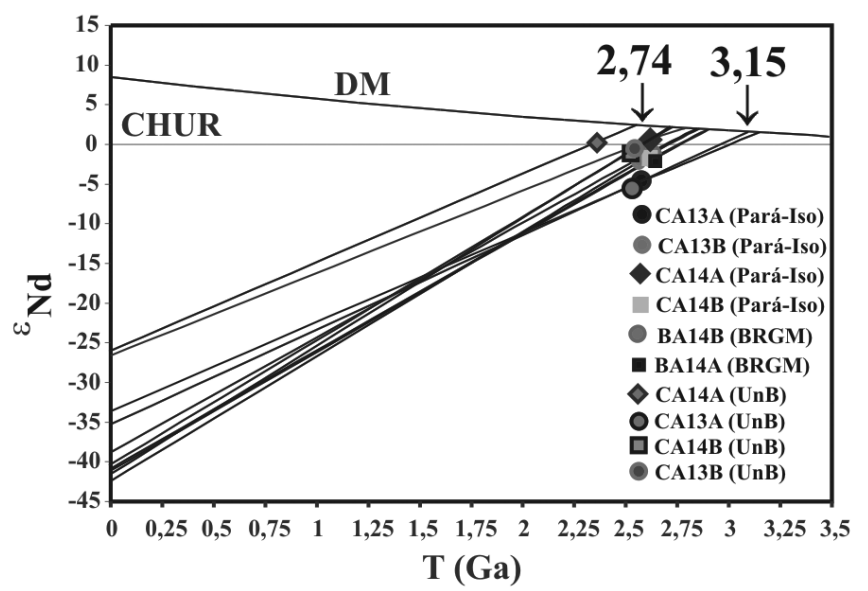

Figura 5 - Diagrama de evolução isotópica do Nd em função do tempo para os granulitos félsicos de Tartarugal Grande (amostras analisadas no Pará-Iso). O valor de $\varepsilon N d_{(T)}$ foi calculado considerando a idade arqueana presumida do protólitos dos granulitos em torno de 2,6 Ga, de acordo com Avelar et al. (2003). DM: Manto Empobrecido, CHUR: Reservatório Condrítico Uniforme (DePaolo 1981). 


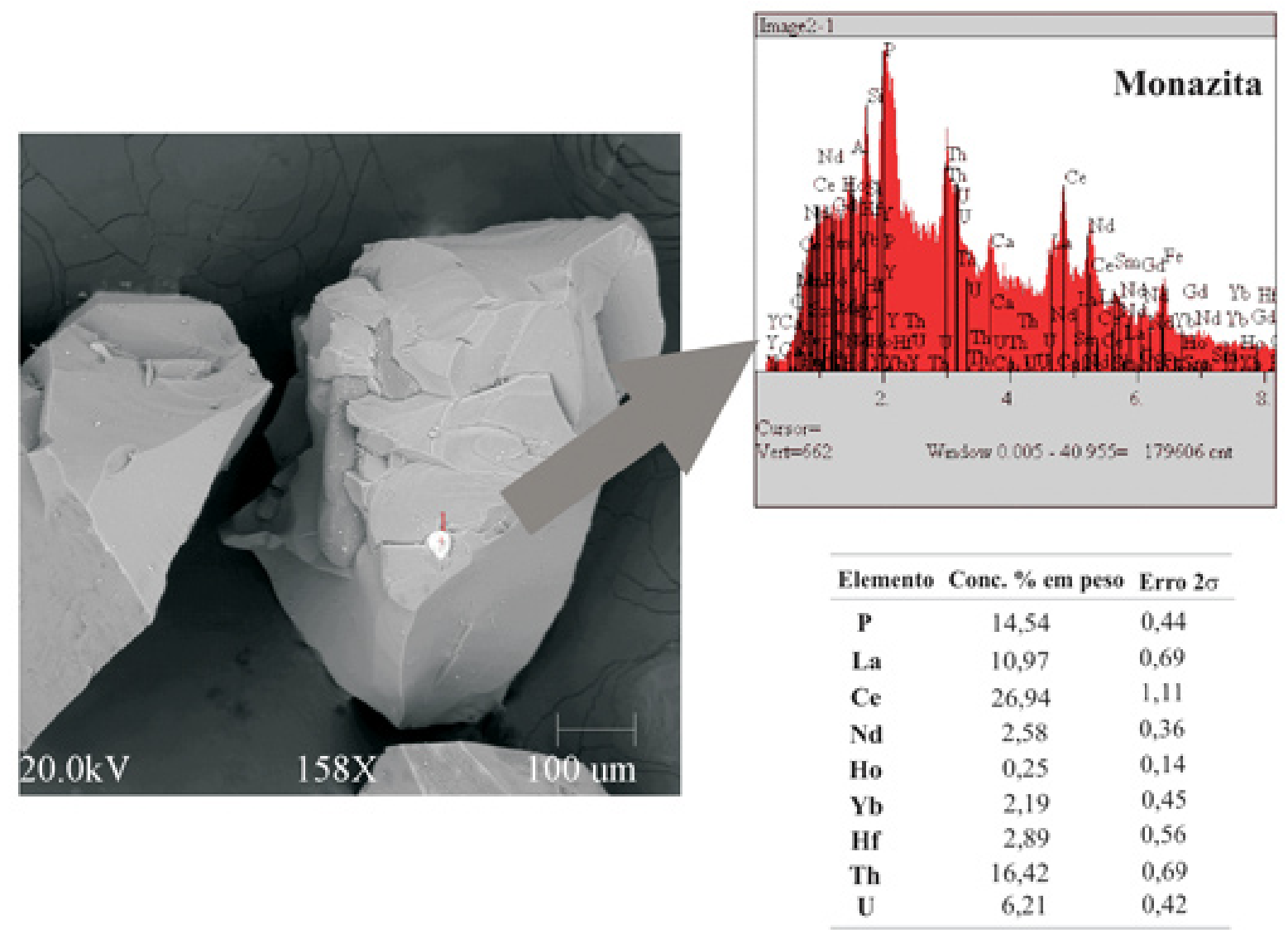

Figura 6 - Fragmento de granada da amostra BA14A com inclusão de monazita. Imagem de elétrons retro-espalhados obtida em microscópio eletrônico de varredura, acompanhada de espectro EDS da inclusão identificando os picos característicos da monazita (imagem e espectro EDS realizadas no laboratório de Microscopia Eletrônica - LABMEV, do Instituto de Geociências da UFPA).

tação do evento metamórfico granulítico como tendo acontecido no final da Orogênese Transamazônica não inviabiliza a possibilidade de um evento metamórfico de alto grau ter afetado as unidades da região central do Amapá ainda no final do Arqueano. Precisam-se de estudos detalhados de geotermobarometria para poder identificar se foi apenas um ou vários eventos metamórficos que atuaram em épocas diferentes na região investigada.

Não foi possível determinar idades isocrônicas em rocha total porém os dois alinhamentos com idades em torno de 2,99 Ga e 1,97 Ga retratam provavelmente a evolução do sistema $\mathrm{Sm}-\mathrm{Nd}$ de rochas arqueanas afetado de forma diferenciada por um evento granulítico tardi-transamazônico.

As idades-modelo $\mathrm{Nd} \mathrm{T}_{(\mathrm{DM})}$ determinadas para os granulitos félsicos da região central do Amapá definiram um intervalo entre 3,15 Ga e 2,79 Ga. Os valores negativos de $\varepsilon_{\mathrm{Nd}(2,6 \mathrm{Ga})}$ indicam um longo tempo de residência crustal para os protólitos, porém, no caso da amostra CA14A, uma participação significativa de material juvenil na fonte do protolito é sugerido pelo valor positivo de $\varepsilon_{\mathrm{Nd}(2,6 \mathrm{Ga})}$. Os resultados geocronológicos confirmam a existência de um evento de diferenciação manto/crosta no Mesoarqueano na região central do Amapá, já eviden- ciado por Sato \& Tassinari (1997), Lafon et al. (2000), e Avelar et al. (2001, 2003). Esse evento de acresção crustal mesoarqueano foi também evidenciado em outras áreas do bloco Amapá (Rosa-Costa et al. 2006), assim como na Província Mineral de Carajás (Macambira \& Lafon 1995, Cordani \& Sato 1999, Tassinari \& Macambira 1999, Souza et al. 2001).

CONCLUSÕES Nesse trabalho, o procedimento experimental do método Sm-Nd utilizado no Pará-Iso foi apresentado detalhadamente para poder ser utilizado como referencia pelos usuários do laboratório.

A datação Sm-Nd, no Pará-Iso, de granulitos félsicos da área de Tartarugal Grande forneceu idades isocrônicas rocha total-granada de $2017 \pm 12$ Ma, 1981,6 \pm $2,8 \mathrm{Ma}$ e $2018 \pm 2,3 \mathrm{Ma}$. A análise das mesmas amostras na UnB indicaram idades de $2037 \pm 8,4 \mathrm{Ma}, 1988 \pm$ $11 \mathrm{Ma}$ e $2013 \pm 15 \mathrm{Ma}$, respectivamente. Os resultados analíticos dos dois laboratórios mostraram uma boa reprodutibilidade para as amostras de rocha total, porém no caso dos concentrados de granadas, algumas amostras apresentaram diferenças significativas de composição isotópica e de concentração. Essas diferenças são consideradas como de origem geológica e não analítica e são provavelmente uma conseqüência de heterogeneidades 
químicas nas frações de minerais analisadas, bem como da presença de micro-inclusões de minerais ricos em elementos terras raras leves, como Ce, La e outras. (Moyes \& Groenewald 1996, Thöni 2002).

Esses resultados indicam que temperaturas acima de $700^{\circ} \mathrm{C}$ foram alcançadas pelos granulitos de Tartarugal Grande entre 2,04-1,98 Ga, comprovando, junto com uma idade $\mathrm{Pb}-\mathrm{Pb}$ em zircão de $2053 \pm 1$ Ma de um plúton charnoquítico da mesma área (Lafon et al. 2001), uma idade tardi-Transamazônica para o evento de alto grau de metamorfismo, na região nordeste do Bloco Arqueano Amapá. Esse evento é contemporâneo do evento metamórfico de UAT identificado na região noroeste do Suriname, também de idade tardi-Transamazônica (Delor et al. 2003b). As idades modelo entre 3,15 Ga e 2,79 Ga constituem mais um registre do evento principal de acresção crustal mesoarqueano, já identificado na porção sudeste do Escudo das Guianas.

Agradecimentos Este trabalho é uma contribuição ao projeto PRONEX/CNPq do Instituto de Geociências da UFPA (projeto 103-98). Elma Oliveira agradece à CAPES pela concessão de uma bolsa de mestrado. Os autores agradecem à Karina L. Vieira pela ajuda na confecção dos mapas, ao Prof. Cláudio Lamarão pelas análises por microscopia eletrônica de varredura e ao Prof. Moacir Macambira e aos dois revisores pelos valiosos comentários.

\section{Referências}

Avelar V.G., Lafon J.M., Delor C. 2001. Geocronologia Pb-Pb em zircão e Sm-Nd em rocha total da porção centro-norte do Amapá. Implicações para a evolução geodinâmica do Escudo das Guianas. In: SBG, Simp. de Geol. da Amazônia, 7. Belém, atas, CD-ROM.

Avelar V.G. 2002. Geocronologia Pb-Pb em zircão e Sm-Nd em rocha total da porção centro-norte do Estado do Amapá. Implicações para a Evolução Geodinâmica do setor oriental do Escudo das Guianas. Tese de Doutorado, Instituto de Geociências, Universidade Federal do Pará, 213p.

Avelar V.G., Lafon J.M., Delor C., Guerrot C., Lahondére D. 2003. Archean crustal remmants in the easternmost part of the Guiana Shield: $\mathrm{Pb}-\mathrm{Pb}$ and $\mathrm{Sm}-\mathrm{Nd}$ geochronological evidence for Mesoarchean versus Neoarchean signatures. Géologie de la France, 2-3-4:83-100.

Borba A.W., Mizusaki A.M.P., Silva D.R.A., Koester E., Noronha F.L., Casagrande J. 2006. Provenance of the Neoproterozoic Marica Formation (Sul-rio-grandense Shield, Southern Brazil): Petrographic and Sm-Nd isotopic constraints. Gondwana Research, 9:464-474.

Burton K.W. \& O'nions R.K. 1991. High-resolution garnet chronometry and the rates of metamorphic processes. Earth Planet. Sci. Lett., 107:649-671.

Burton K.W., Kohn M.J., Cohen A.S., O'nions R.K. 1995. The a relative diffusion of $\mathrm{Pb}, \mathrm{Nd}, \mathrm{Sr}$ and $\mathrm{O}$ in garnet. Earth Planet. Sci. Lett., 133:199-211.

Carvalho J.M.A., Rosa-Costa L.T., Ricci P.S.F., Vasquez M.L., Klein E.L., Vale A.G.V., Macambira E.M.B. 2001. Geologia da área do Projeto RENCA - sudeste do Escudo das Guianas. In: SBG, Simp. de Geol. da Amazônia, 7. Belém, atas, CD-ROM.

Cordani U.G, Tassinari C.G.G, Teixeira W., Basei M.A.S., Kawashita K. 1979. Evolução tectônica da Amazônia com base em dados geocronológicos. In: Congresso Geológico Chileno, 2, Santiago, Actas, v. 4, p.137-148.

Cordani U.G. \& Neves B.B.B. 1982. The geologic evolution of South America during the Archean and Early Proterozoic. Rev. Bras. de Geoc., 12:78-88.

CordanI U.G. \& Sato K. 1999. Crustal evolution of the South American Platform, based on Nd isotopic systematics on granitoid rocks. Episodes, 22(3):167-173.
Costa J.B.S. \& Hasui Y. 1997. Evolução geológica da Amazônia. In: Costa M.L.C. \& Angélica R.S. (coords.) Contribuição à Geologia da Amazônia. SBG-NO, p.15-90.

Cohen A.S., O'nions R.K., Siegenthaler R., Griffin W.L. 1988. Chronology of the pressure-temperature history recorded by a granulite terrain. Contrib. Mineral. Petrl., 98:303-311.

CPRM. Serviço Geológico do Brasil. 2004. Carta geológica do Brasil 1:1.000.000,00- Folha NA.22- Macapá. CDROM.

Delor C., Lahondère D., Egal E., Lafon J.M, Cocherie A., Guerrot C., Rossi P., Trufert C., Theveniaut H., Phillips D., Avelar V.G. 2003a. Transamazonian crustal growth and reworking as revealed by the 1:500,000-scale geological map of French Guiana (2nd edition). Géologie de la France, 2-3-4:5-57.

Delor C., Roever E.W.F. De, Lafon J.M., Lahondère D., Rossi P., Cocherie A., Guerrot C., Potrel A. 2003b. The Bakhuis ultrahigh-temperature granulite belt (Suriname): II. Implications for late the Transamazonian crustal stretching in a revised Guiana Shield framework. Géologie de la France, 2-3-4:207-230.

DePaolo D.J. 1981. A neodymium and strontium isotopic study of the Mesozoic calc-alcaline granitic batholiths of the Sierra Nevada and Penisular Ranges, California. Journal of Geophysical Research, 86(B11):1047010488.

DePaolo D.J. 1988. Neodymiun isotope geochesmistry- In introduction. Springer-Verlag, $198 \mathrm{p}$.

De Roever E.W. F., Lafon J. M., Delor C., Cocherie A., Rossi P., Guerrot C., Potrel A. 2003. In: BRGM - SGF (eds.) The bakhuis ultrahigh temperature granulite belt (Suriname): I Petrological and geochronological evidence for a counterclockwise- $P$-t parth at 2.07-2.05 Ga. Geologie de la France - Special Guiana Shield, p.175-206.

Faraco M.T.L., Marinho P.A.C., Moura C.A.V., Macambira M.J.B., Pimentel M. M. 2006. Novos dados geocronológicos no Ampá-NNW do Pará e sua contribuição no entendimento geodinâmico da poção SE do Escudo das Guianas. In: SBG, Simp. de Geol. da Amazônia, 9, Belém, atas, CD-ROM. 
Faure G. \& Mensing T.M. 2005. Isotopes: Principles and Applications. $3^{\text {a }}$ ed., New York, John Wiley, 897p.

França Z.T.M., Tassinari C.C.G., Cruz J.V., Alfredo Y.A., Arama V., Rodrigues B. N. 2006. Petrology, geochemistry and $\mathrm{Sr}-\mathrm{Nd}-\mathrm{Pb}$ isotopes of the volcanic rocks from Pico Island-Azores (Portugal). Journal of Volcanology and Geothermal Research, 156:71-89.

Gibbs A.K. \& Olszewski W.J. 1982. Zircon U-Pb ages of Guyana greenstone-gneiss terrane. Precambrian Research, 17: 199-214.

Gioia S.M.C.L. \& Pimentel M.M. 2000. The Sm-Nd isotopic method in the geochronology laboratory of the University of Brasília. An. Acad. Bras., 72:220-245.

Gruau G., Martin H., Leveque B., Capdevilla R. 1985. Rb-Sr and Sm-Nd geochronology of Lower Proterozoic granitegreenstone terrains in French Guyane, South America. Precambrian Research., 30:63-80.

Hasui Y., Haraly N.L.E., Schobbenhaus C. 1984. Elementos geofísicos e geológicos da região amazônica: subsídios para o modelo geotectônico. In: SBG, Simp. Geol. Amaz., 2, Manaus, Atas, p.129-148.

Hayward J.A. 1983. Rb-Sr geochronology and the evolution of some paraluminous granites in New Hampshire. M.S. Thesis, University of New Hampshire, Durham, 108p.

Hensen B.J \& Zhou BO. 1995. Retention of isotopic memory in garnets partially broken down during an overprinting granulite-faceis metamorphism: implications for the SmNd closure temperature.Geology, 23(3):225-228.

Jagoutz E. 1988. Nd and Sr systematics in an eclogite from Tanzania: evidence for frozen mineral equilibria in the continental lithosphere. Geochim. Cosmochim. Acta, 52:1285-1293.

João X.S.J. \& Marinho P.A.C. 1982b. Catametamorfitos Arqueanos da região centro-leste do Território Federal do Amapá. In: SBG, Simp. de Geol. da Amazônia, 1, Belém, Atas, SBG. v.2. p. 207-228.

Jung S. \& Mezger K. 2003. Petrology of basement-dominated terranes: I. Regional metamorphic T-t path from $\mathrm{U}-\mathrm{Pb}$ monazite and Sm-Nd garnet geochronology (Central Damara Orogen, Namibia). Chemical Geology, 198:223247.

Kelley W.J. 1980. Nd isotopic of the massabesic gneiss: southeast New Hampshire. M.S. Thesis, University of New Hampshire, Durham, 121p.

Lafon J.M., Rossi P., Delor C., Avelar V.G., Faraco M.T.L. 1998. Novas testemunhas de relíquias arqueanas na crosta continental paleoproterozóica da Província MaroniItacaiúnas (Sudeste do Escudo das Guianas). In: Cong. Bras. Geol., 40, Belo Horizonte, Anais, p.64.

Lafon J.M., Avelar V.G., Rossi Ph., Delor C., Guerrot C., Pidgeon R.T. 2000. Geochronological evidence for reworked Neoarchean crust during Transamazonian orogeny $(2,1$ $\mathrm{Ga}$ ) in the southeastern Guiana Shield. In: International Geological Congress, 31, Rio de Janeiro, Abstracts, CDROM.

Lafon J.M., Rossi P., Delor C., Barbosa O.S. 2001. Granulitos tardi-Transamazônicos $(2,06 \mathrm{Ga})$ na região norte do Estado do Amapá: o charnoquito de Calçoene. In: SBG, Simp. de Geol. da Amazônia, 7, Belém, atas, CD-ROM.

Lafon J.M., Delor C., Théveniaut H., Krymsky R., Tavares
R.P.S., Roig J.Y. 2003. Isotopic deciphering of Rhyacian crustal evolution along the northern oyapok river new constraints from $\mathrm{Sm}-\mathrm{Nd}, \mathrm{U}-\mathrm{Pb}$ and $\mathrm{Pb}-\mathrm{Pb}$ geochronology. In: SBG, Simp. Geol. Amazônia, 8, Manaus, Extended Abstract, CD-ROM.

Lima M.I.C., Bezerra P.E.L., Araújo H.J.T. 1991. Sistematização da geologia do Estado do Amapá. In: SBG, Simp. de Geol. da Amazônia 3, Belém, Boletim de Resumos Expandidos, p.322-335.

Lima M.I.C., Oliveira E.P., Tassinari C.C.G. 1982. Cinturões granulíticos da porção setentrional do Cráton Amazônico. In: SBG, Simp. de Geol. da Amazônia, 1, Belém, Atas, v.1, p. 147-162.

Ludwig K.R. 2000. Users manual for ISOPLOT/EX a geochronological toolkit for Microsoft Excel (version 2.33d). Berkeley Geochronology Center, Special Publication 1, 43p.

Macambira M.J.B \& Lafon J.M. 1995. Geocronologia da Província Mineral de Carajás; Síntese dos dados e novos desafios. Bol. do Museu Paraense Emílio Goeldi., Ciências da Terra, 7:263-288.

Maboko M.A.H. \& Nakamura E. 1995. Sm-Nd garnet ages from the Uluguru granulite complex of Eastern Tanzania: further evidence for post-metamorphic slow cooling in the Mozambique belt. Precambrian Research, 74:195-202.

Mayer A., Hofmann A.W., Sinigoi S., Morais E. 2004. Mesoproterozoic $\mathrm{Sm}-\mathrm{Nd}$ and $\mathrm{U}-\mathrm{Pb}$ ages for Kunene Anorthosite Complex of SW Angola. Precambrian Research, 133:187-206.

MacReath I. \& Faraco M.T.L. 2006. Paleoproterozoic greenstone-granite belts in northern Brazil and the former Guyana Shield-West African craton province. Revista do Instituto de Geociências-USP. Geol. USP Sér. Cient., 5(2):49-63.

Mezger K., Essene E.J., Halliday A.N. 1992. Closure temperature of the Sm-Nd system in metamorphic garnet. Earth Planet. Sci. Lett., 113:397-409.

Montalvão R.M.G. \& Tassinari C.C.G. 1984. Geocronologia pré-cambriana do Território Federal do Amapá (Brasil). In: SBG/MME-DNPM, Simp. Amaz., 2, Manaus, Atas, p.54-57.

Moura C.A.V. 1992. Geochronolgy and geochemistry of the basement orthogneisses of the Araguaia belt. Brazil. M.S. Thesis, University of New Hampshire, 236p.

Moyes A.B \& Groenewald P.B. 1996. Isotopic constraints on Pan-African metamorphism in Dronning Maud Land, Antarctica. Chemical Geology, 129:247-256.

Nogueira S.A.A., Bettencourt J.S., Tassinari C.C.G. 2000. Geochronology of the Salamangone gold deposit hostrocks, Lourenço district, Amapá, Brazil. Rev. Bras. de Geoc., 30(2):261-264.

Peng J.-T, Hu R.-Z., Brunard P.G. 2003. Samarium-neodymium isotope systematics of hydrothermal calcites from the Xikuangshan antimony deposit (Hunan, China): the potencial of calcite as a geochronometer. Chemical Geology., 200:129-136.

Pimentel M.M., Spier C. A., Filho C. F. F. 2002. Estudo Sm-Nd do complexo máfico-ultramáfico Bacuri, Amapá: Idade da intrusão, metamorfismo e natureza do magma original. 
Rev. Bras. de Geoc,. 32(3):371-376.

Ricci P.S.F., Carvalho J.M.A., Rosa-Costa L.T., Klein E.L., Vasquez M.L., Vale A.G., Macambira E.M.B., Araújo O. J.B., 2001. Geologia e Recursos Minerais do projeto RENCA- Fase I., CPRM. In: Simp. Geol. da Amazônia,7, Belém, atas, CD-ROM.

Rosa-Costa L.T., Vasquez M.L., Carvalho J.M.A., Ricci P.S.F., Lafon J.M. 2001. Geocronologia Preliminar do Arqueano e Paleoproterozóico do NW do Pará/SW do Amapá - Escudo das Guianas. In: SBG, Simp. de Geol. da Amazônia, 7, Belém, Resumos expandidos, CDROM.

Rosa-Costa L. T., Ricci P.S.F., Lafon J. M., Vasquez M. L., Carvalho J. M. A., Klein E. L., Macambira E.M.B. 2003. Geology and geochronology of Archean and Paleoproterozoic domains of the southeastern Amapá and northwestern Pará, Brazil-southeastern Guiana Shield. Géologie de la France, 2-3-4:101-120.

Rosa-Costa L. T., Lafon J.M., Delor C. 2006. Zircon geochronology and Sm-Nd isotopic study: further constraints for the Archean and Paleoproterozoic geodynamic evolution of the southeastern Guiana Shield, north of Brazil. Gondwana Res., 10:277-300.

Santos J.O.S., Hartmann L.A., Gaudette H.E., Groves D.I., Mcnaughton N.J., Fletcher I.R. 2000. A new understanding of the provinces of the Amazon Craton based on integration of field mapping and $\mathrm{U}-\mathrm{Pb}$ and $\mathrm{Sm}-\mathrm{Nd}$ geochronology. Gondwana Research, 3(4):453-488.

Sato K. \& Tassinari C.C.G. 1997. Principais eventos de acreção continental no Cráton Amazônico baseados em idademodelo Sm-Nd, calculada em evoluções de estágio único e estágio duplo. In: Costa M.L.C. \& Angélica R.S. (coords.) Contribuição à Geologia da Amazônia. SBG-NO, p. 91142.

Sato K., Tassinari C.G., Kawashita K., Petronilho L. 1995. O método Geocronológico Sm-Nd no IG/USP e suas aplicações. Anais da Academia Brasileira de Ciências, 67(3): 313-336.

Souza Z.S., Potrel A., Lafon J.M., Althoff F.J., Pimentel M.M., Dall'Agnol R., Oliveira C.G. 2001. Nd, Pb and Sr isotopes in the Identidade belt, an Archaean greenstone belt of the Rio Maria region (Carajás Province, Brazil): implications for the Archaean geodynamic evolution of the Amazonian Craton. Precambrian Research, 109:293315.

Stoeser D.B. \& Frost C.D. 2006. Nd, Pb, Sr, and O isotopic characterization of Saudi Arabian Shield Terranes. Chemical Geology, 226:163-188.
Sun S., Warren R.G., Shaw R.D. 1995. Nd isotope study of granites from the Arunta Inlier, central Austrália: constraints on geological models and limitation of the method. Precambrian Research, 71:301-314.

Tassinari C.C.G. \& Macambira M.J.B. 1999. Geochronological provinces of the Amazonian Craton. Episodes, 22(3): $174-182$.

Tassinari C.C.G., Bettencourt J.S., Geraldes M.C., Macambira M.J.B., Lafon J.M. 2000. The Amazonian Craton. In: Cordani U.G., Milani E.J., Filho A.T., Campos D.A. (eds.) Tectonic Evolution of South America. Rio de Janeiro, International Geological Congress, 31, Rio de Janeiro, SBG, 41-95p.

Tassinari C.C.G. \& Macambira M.J.B. 2004. A evolução tectônica do Cráton Amazônico. In: MantessO-Neto V., Bartonelli A., Carneiro C.D.R., Brito Neves B.B. (eds.) Geologia do Continente Sul-Americano: Evolução da Obra de Fernando Flávio Marques de Almeida. São Paulo: Beca - SP, p.471-485.

Teixeira W., Tassinari C.C.G., Cordani U.G., Kawashita K. 1989. A review of the geochronology of the Amazonian Craton: Tectonic implications. Precambrian Research, 42:213-227.

Thöni M. \& Jagoutz E. 1992. Some new aspects of dating eclogites in orogenic belts: $\mathrm{Sm}-\mathrm{Nd}, \mathrm{Rb}-\mathrm{Sr}$, and $\mathrm{Pb}-\mathrm{Pb}$ isotopic results from the Austroalpine Saualpe and Koralpe type-locality (Carinthia/Styria, southeastern Austria). Geochim. Cosmochim. Acta, 56:347-368.

Thöni M. 2002. Sm-Nd isotope systematics in garnet from different lithologies (Eastern Alps): age results, and an evaluation of potential problems for garnet $\mathrm{Sm}-\mathrm{Nd}$ chronometry. Chemical Geology, 185:255-281.

Vasquez M.L. \& Lafon J.M. 2001. Magmatismo tipo A de 1,75Ga na porção oriental do Escudo das Guianas - Estados do Amapá e Pará, Brasil. In: SBG, Simp. de Geol. da Amazônia, 7. Belém, Resumos Expandidos, CD-ROM.

Vanderhaeghe O., Ledru P., Thiéblemont D., Egal E., Cocherie A., Tegyey M., Milési J.J. 1998. Contrasting mechanism of crustal growth Geodynamic evolution of the Paleoproterozoic granite-greenstone belts of French Guyana. Precambrian Research, 92:165-193.

Manuscrito ID 9720

Submetido em 07 de novembro de 2007 Aceito em 15 de junho de 2008 Sistema eletrônico de submissão 